Pensares em Revista, ISSN 2317-2215

\title{
POSSÍVEIS CONTRIBUIÇÕES DA TEORIA E DA CRÍTICA LITERÁRIA PARA AULAS DE LITERATURA
}

\author{
Alberto ROIPHE \\ (Universidade Federal de Sergipe) \\ albertoroiphe@bol.com.br
}

\begin{abstract}
Resumo: O artigo busca demonstrar possíveis contribuições da teoria e da crítica literária para aulas de literatura. Para tanto, parte-se da análise de textos literários de diferentes fases da literatura brasileira, tendo como fundamentação teórica pressupostos da Estética da Recepção da Escola de Constança, na Alemanha, a fim de que se possa refletir sobre o reconhecimento da teoria literária e da crítica literária para a formação de professores e para a elaboração de propostas práticas relacionadas ao ensino e à aprendizagem da literatura. Essas propostas envolvem poemas de Carlos Drummond de Andrade e de Antonio Cícero e a importância da relação texto e contexto para ampliar os sentidos de compreensão das obras.
\end{abstract}

Palavras-chave: Teoria literária. Crítica literária. Formação de professores de literatura. Ensino e aprendizagem de literatura.

\section{POSSIBLE CONTRIBUTIONS OF THEORY AND LITERARY CRITICISM TO LITERATURE CLASSES}

Abstract: This paper demonstrates possible contributions of theory and literary criticism to literature classes. Therefore, it starts with the analysis of literary texts during different phases of Brazilian literature using as the theoretical foundation the assumptions proposed by the Aesthetic Reception of Constance School in Germany. The aim of such a procedure is to reflect on the recognition of literary theory and literary criticism as important topics for teacher training and for the development of practical suggestions for the teaching and learning of literature. These suggestions involve, on the one hand, poems written by Carlos Drummond de Andrade and Antonio Cicero and, on the other, the importance of relation between text and context in order to enhance the student's understandings of the possible meanings conveyed by poems.

Keywords: Literary theory. Literary criticism. Educating literature teachers. Teaching and learning literature. 


\section{Introdução}

Quando se observa a diversidade de textos literários existentes nas mais variadas literaturas, é comum notar, por parte dos leitores em sala de aula, a frequente necessidade de orientação para realizarem suas análises. Essas orientações, de certa forma, fazem parte dos critérios para a formação universitária de um professor de literatura quando estuda, durante o curso de Letras, textos de teoria e de crítica literária.

Por esses motivos, relacionar textos teóricos e textos críticos ao ensino e à aprendizagem da literatura é lembrar ao professor que os estudos realizados em sua formação inicial são, certamente, uma contribuição para elaborarem suas aulas. A contribuição ocorre, sobretudo, quando se leva em conta que tais estudos instigam, por meio da análise de obras, a curiosidade a respeito da organização estética da linguagem literária. Essa articulação entre teoria, crítica e texto literário permite ao professor, como afirma Sandra Nitrini, "ensinar de maneira aderente ao texto, evitando teorizar demais e procurando mostrar de que maneira os conceitos lucram em ser apresentados como instrumentos de prática imediata, isto é, de análise" (NITRINI, 1994, p. 473).

Assim sendo, o propósito deste artigo é evidenciar diálogos entre teoria, postura crítica e trabalho com o texto literário em sala de aula, de maneira a possibilitar ao professor uma reflexão sobre a conveniência de tal articulação durante a elaboração de suas aulas.

\section{1 - O papel crítico da leitura}

O teórico francês Roland Barthes (2011), no texto "O que é a crítica", afirma que o objeto da crítica é o discurso de um outro, que a crítica é um discurso sobre esse discurso do outro, caracterizando-se, portanto, como uma forma metalinguística. Para Barthes, a crítica apresenta duas espécies de relação: a relação da linguagem crítica com a linguagem do autor observado e a relação da linguagem-objeto (a linguagem da obra) com o mundo. Para o teórico francês, é o "atrito" dessas duas linguagens que define a crítica. Nesse caso, a crítica não busca provas científicas sobre o texto, e sim o levantamento de hipóteses sobre 
ele, o que é fundamental para a atuação do professor de literatura em sala de aula.

Nesse ponto, a crítica pode contribuir com o trabalho pedagógico, já que o leitor, frequentemente, como afirma o crítico literário Manoel da Costa Pinto (2012), busca indicações e olhares sobre elementos de uma obra. Para demonstrar essa necessidade dos leitores, Manoel da Costa Pinto estabelece uma analogia entre os textos que analisam e interpretam os textos de crítica literária e as mesas redondas de futebol:

Tem quem goste tanto de futebol que só ver as partidas não basta, a pessoa tem de ver a mesa-redonda sobre o assunto. A crítica literária é como a mesa redonda da TV. Não existe porque se quer um blá-blá-blá interminável, mas porque se espera perceber camadas novas de significação que não se havia notado e para entender a razão de se ter gostado daquilo. (Idem, p. 13)

É por isso que, em contato com os textos da crítica sobre um poema de Olavo Bilac, um romance de Machado de Assis, ou uma peça de teatro de Martins Pena, o professor amplia os sentidos do que apreciou durante sua leitura solitária. Lembrando sobre essa necessidade de análise por parte do leitor, o poeta e teórico da literatura Ezra Pound afirma que:

O crítico que não tira suas próprias conclusões, a propósito das medições que ele mesmo fez, não é digno de confiança. Ele não é medidor, mas um repetidor das conclusões de outros homens. (1994, p. 33)

É sobre a leitura da obra que o teórico insiste que "Se alguém quiser saber alguma coisa sobre poesia, deverá fazer uma das duas coisas ou ambas. I. É, OLHAR para ela ou escutá-la. E, quem sabe, até mesmo pensar sobre ela." (Idem, p. 34). [grifos do autor]

Dessa maneira, valoriza-se o papel do leitor como aquele que deve realizar suas próprias análises de uma obra, tendo a crítica a função de oferecer uma experiência de prolongamento da obra, e não a leitura correta ou, como diz Roland Barthes: "a crítica é apenas uma metalinguagem, isto quer dizer que sua tarefa não é absolutamente descobrir 'verdades' mas somente 'validades'”. (2011, p. 161) 
É por meio da própria leitura e do acesso a críticas sobre os textos literários, portanto, que o professor poderá chegar a diferentes planos de uma obra e, então, poderá propor sua própria versão, considerando os elementos que encontrou.

\section{2 - Entre a crítica, a teoria literária e a aula de literatura}

Considerando-se que a preparação de uma aula exige do professor a leitura apurada do texto literário escolhido, parece conveniente recorrer, aqui, aos pressupostos da Estética da Recepção da Escola de Constança, como se sabe, corrente da teórica que tem o leitor como foco de interesse.

Esse interesse é demonstrado por Wolfgang Iser, ao afirmar que o texto literário possui uma "estrutura de apelo". Portanto, quando o leitor percebe os sentidos presentes na linguagem de uma obra literária, ele tem um papel essencial na prática da leitura.

O que é importante frisar é que esses sentidos não se limitam ao próprio texto, eles, na verdade, se estendem ao contexto de sua produção e de sua recepção. É por esse motivo que Hans Robert Jauss (1994), em seu estudo $A$ história da literatura como provocação à teoria literária, aponta que, enquanto ocorre a recepção de uma obra e, consequentemente, a provocação de seus efeitos, é que a natureza histórica da literatura se manifesta. Com essa afirmação, Jauss anuncia que a leitura de uma mesma obra literária realizada em diferentes épocas provocará diferentes efeitos a serem contemplados pelos seus leitores. É por isso que se pode observar que uma obra é "viva", entendendo-se que isso é o que se chama de atualização da obra, já que em cada novo contexto ocorrerá uma nova leitura daquela obra. O contexto histórico e o contexto real do momento da leitura, a historicidade e a atualização, se fundem, e é o leitor o sujeito capaz de fundi-los e de percebê-los.

É a partir dessas reflexões de Jauss, que se observa o contexto como elemento inerente à estrutura do texto literário, considerando não só o contexto concebido em sentido amplo, ao apoiar-se em aspectos históricos e sociais, mas também em sentido restrito, ao se levar em conta experiências que envolvem o autor e o leitor. 
Quando se considera, então, a relação ensino/aprendizagem, uma referência obrigatória para se pensar o contexto é Paulo Freire que, ao refletir sobre "a importância do ato de ler", destaca o valor atribuído a esse aspecto, quando afirma que "a compreensão do texto a ser alcançada por sua leitura crítica implica a percepção das relações entre o texto e o contexto" (1999, p.11). É assim que $\mathrm{o}$ grande educador brasileiro vê a possibilidade de linguagem e realidade se prenderem dinamicamente.

Relacionando esse pensamento de Paulo Freire com a ideia de atualização da obra que, segundo Jauss, ocorre a cada leitura, é possível notar que, à medida que um leitor analisa e interpreta um texto literário, ele compara o contexto em que o texto foi produzido com o contexto de sua leitura, garantindo uma leitura crítica daquilo que lê.

O texto literário, como as demais artes, oferece elementos, em sua própria linguagem, que determinam os aspectos contextuais. Por isso, estudar literatura, como lembra Cyana Leahy-Dios, "implica entender que a arte literária se situa em determinado momento no tempo e no espaço, carreando questões sociais, culturais, políticas e econômicas inevitáveis e preciosas." (2001, p. 56)

É essencial, portanto que, ao estudar literatura, o leitor busque estabelecer relações entre o texto e o contexto de sua produção e de leitura. Afinal, como afirma Samir Meserani:

E é sabido que o leitor lê baseado em seu repertório cultural, em sua experiência textual e capacidade linguística, de tal modo que cada leitura é uma leitura, mesmo que as diferenças entre elas sejam mínimas e sem grandes consequências para a compreensão do texto em termos práticos. (MESERANI, 1995, p. 43)

O texto literário guarda em si, frequentemente, elementos históricos, políticos, ideológicos, filosóficos e religiosos, entre outros, que passam a fazer parte da obra literária e que criam para o leitor o elo entre o texto e o contexto. Para entendermos tal elo, tomaremos como exemplo o poema "Virgem" (2008, p. 75), escrito por Antonio Cícero e musicado pela cantora Marina Lima. 


\section{VIRGEM}

As coisas não precisam de você:

Quem disse que eu tinha que precisar?

As luzes brilham no Vidigal

E não precisam de você;

Os dois irmãos

Também não.

O Hotel Marina quando acende

Não é por nós dois

Nem lembra o nosso amor.

Os inocentes do Leblon,

Esses nem sabem de você

Nem vão querer saber

E o farol da ilha só gira agora

Por outros olhos e armadilhas:

O farol da ilha procura agora

Outros olhos e armadilhas.

Para proceder à análise do texto, é preciso lembra que o projeto modernista foi tão importante para o Brasil, que suas produções ainda são referências para as mais variadas expressões artísticas contemporâneas. Quando se examinam, por exemplo, algumas letras da música popular brasileira, nota-se o quanto esses diálogos são fortes. Tais aproximações entre a literatura e a música tornam-se, assim, uma excelente oportunidade de trabalho, em sala de aula, com as canções que o aluno ouve em seu cotidiano. Essas canções, quando associadas a outras formas literárias, permitem que se contemple tanto a organização estética da linguagem, como a sua função social, política e cultural, elementos sempre presentes em uma obra artística.

O diálogo entre a literatura e a música ocorre desde a Antiguidade clássica. Basta observar que, na poesia lírica grega, os versos eram acompanhados pela lira, o instrumento musical que justifica, inclusive, a própria denominação literária relativa à poesia: "lírica". Também as epopeias gregas, a Ilíada e a Odisseia, as duas grandes narrativas poéticas atribuídas a Homero, são obras divididas não em capítulos, mas em cantos. Isso porque, de fato, essas obras eram divulgadas 
pelos aedos, "cantadores" que viajavam por todo o território grego, expressando essas obras oralmente. Foi apenas séculos mais tarde que ambas foram manuscritas e, muito tempo depois, impressas em papel.

$\mathrm{Na}$ tradição poética da língua portuguesa, conforme lembra o estudioso e professor de literatura Ítalo Moriconi (2002), a relação entre a literatura e a música tem início na Idade Média, razão pela qual é possível observar, nesse caso, as cantigas de amor e de amigo, que marcaram o início da poesia portuguesa, e que eram acompanhadas pela música. Entretanto, "as cantigas", segundo o estudioso, com o passar do tempo, se mantiveram apenas na forma escrita, porque a melodia não persistiu.

$\mathrm{Na}$ contemporaneidade, como afirma Moriconi, "muitos textos de diversos (...) poetas foram musicados como canções da MPB e do rock" (2002, p. 14), como no caso de obras de Camões (pelo grupo Legião Urbana), de Cecília Meireles (por Fagner), de Ferreira Gullar (também por Fagner), para citar alguns. O contrário também ocorreu, quer dizer, algumas canções da MPB e do rock passaram a ter suas letras editadas em livros, como aconteceu com muitos poemas de Vinicius de Moraes, nos anos 70, e de Arnaldo Antunes, nos anos 90, por exemplo.

Partindo-se para a especificidade do poema "Virgem", nota-se que o eu lírico, dirigindo-se ao seu amado, exprime de forma recorrente a concepção de que nada no mundo tem a necessidade de existir em função dele: "as coisas não precisam de você".

Diante dessa imagem, é possível presumir o que se perguntariam leitores e ouvintes que não conhecem a paisagem descrita: Onde fica o Vidigal? Que luzes são essas que brilham? Quem são os dois irmãos? Onde fica o Hotel Marina? Onde é o Leblon? Quem são os inocentes do Leblon? Por que inocentes?

Em resposta a essas questões que, de certa forma, ajudam a problematizar o poema, talvez tudo se torne mais claro na composição, sobretudo quando se parte para a contextualização da "cena". Sabendo-se que se trata de um texto concebido como poema pelo carioca Antonio Cícero, e que se tronou letra de música na voz de sua irmã Mariana Lima, não é difícil perceber que a cena se ambienta no Rio de Janeiro, cidade onde ambos viviam no início dos anos 90 . Esses dados auxiliam o leitor do poema e/ou o ouvinte da canção a perceber que 
uma obra pode se relacionar diretamente com o ambiente em que foi produzida, as condições sociais e culturais que emergem desse ambiente, assim como tantos outros elementos políticos, filosóficos, religiosos que, tantas vezes, motivam os poetas a escrever, e que, de algum modo, estão marcados em seus textos literários.

Na paisagem noturna, revelada pelas luzes que "brilham no Vidigal", pela placa luminosa do "Hotel Marina quando acende" e pelo "farol da ilha", confirmase a visão que se tem na praia do Leblon, bairro da zona sul do Rio de Janeiro, exatamente como descreve o poeta: o morro do Vidigal, o morro Dois Irmãos e o Hotel Marina.

Quando se volta ao texto, torna-se clara, de fato, a percepção do eu lírico, de que nada à sua volta se altera em função da pessoa amada: nem o morro Dois Irmãos, nem as luzes no morro do Vidigal, nem o acender da placa do Hotel Marina, nem o girar do farol da ilha. No entanto, das questões sugeridas de início, as que permanecem são as duas últimas: Quem são os inocentes do Leblon? Por que inocentes?

Em uma aula de literatura, a fim de problematizar o que se lê e, ao mesmo tempo, para não deixar de responder à questão, o professor necessita recorrer a seu repertório de leituras, ou buscar a informação. Nesse caso, na leitura de Alguma Poesia, o primeiro livro de Carlos Drummond de Andrade, o poema "Inocentes do Leblon" poderá indicar uma compreensão para o termo.

\section{INOCENTES DO LEBLON}

Os inocentes do Leblon

Não viram o navio entrar.

Trouxe bailarinas?

Trouxe emigrantes?

Trouxe um grama de rádio?

Os inocentes, definitivamente inocentes, tudo ignoram,

Mas a areia é quente, e há um óleo suave

Que eles passam nas costas, e esquecem. 
Quando se lê o poema, nota-se que os denominados inocentes do Leblon "tudo ignoram", seja o navio, sejam as "bailarinas" e os "emigrantes", seja "um grama de rádio". O poema de Drummond, ao mostrar que os inocentes do Leblon, não estão atentos à arte, à sociedade e à ciência, ignorando tudo, na areia quente da praia, passam nas costas o óleo suave, e esquecem. Esses "definitivamente inocentes" são uma marca de certa renúncia, razão pela qual, também ignoram a relação amorosa presente no poema de Antonio Cícero: "não sabem de você / nem vão querer saber".

Tal marca de renúncia é comentada por Genolino Amado em texto homônimo, "Os inocentes do Leblon", em 1946, no qual o autor baiano faz algumas considerações sobre a obra de Carlos Drummond de Andrade, levantando as condições políticas, sociais e ideológicas para justificar essa renúncia:

(...) o poeta que tudo sente fica assombrado ao encontrar criaturas que não sentem nada, na alegre indiferença da barraca de lona, do banho de sol e do bate-bola. Assombra-se, mas não condena. E condenar por quê? Terão mesmo culpa em ser assim tão inocentes? Mas, o diabo é que esses inocentes estão aumentando em proporções assustadoras. Já não cabem no Leblon. Alastraram-se por toda parte, dando até o ar da sua graça onde menos se espera e se compreende essa forma de inocência diante da vida - nos meios culturais, responsáveis pela formação das ideias guiadoras e dos motivos emocionais com que temos de fixar a nossa posição neste período conclusivo da guerra, quando já se esboçam na consciência de todos os povos as normas e condições do mundo novo. (AMADO, 1946, p. 14)

Essas observações de Genolino Amado contribuem para a compreensão do poema que, sendo trabalhado em sala de aula, precisa, de fato, ser analisado pelo professor de literatura que, então, poderá, conhecendo o texto e seu contexto, por meio da organização da linguagem, explorar os elementos ideológicos, políticos, culturais e sociais levantados pelo autor, provocando perguntas de acordo com sua intencionalidade, de acordo com aquilo que ele quer que seu aluno aprenda.

Diante da dúvida de muitos professores sobre como adquirir o repertório para o trabalho com uma letra de música ou um poema, um conto ou um romance, a primeira resposta é a pesquisa literária. Quanto mais acesso o professor de literatura tiver às obras literárias, às obras de crítica literária e à 
história da literatura, além da leitura em geral, mais repertório terá. O importante é que explore textos que conheça e que, compreendendo a educação como um processo para seus alunos e também para ele, um professor sempre em formação, procure ampliar seu conhecimento de obras literárias, das origens à contemporaneidade, para que, então, possa ter condições de incrementar suas práticas didáticas, envolvendo sempre diferentes textos.

Nesse caso, trata-se de partir para a percepção estética do texto literário, concebendo $o$ ato de ler como forma de produzir sentidos a partir da organização da linguagem literária no curso do tempo, unindo texto e contexto.

Em busca de um argumento de autoridade que confirme essa leitura, o que se encontra é uma reflexão do crítico Antonio Candido que, em Literatura e Sociedade, explica tal relação.

só a [obra] podemos entender fundindo texto e contexto numa interpretação dialeticamente íntegra, em que tanto o velho ponto de vista que explicava pelos fatores externos, quanto o outro, norteado pela convicção de que a estrutura é virtualmente independente, se combinam como momentos necessários no processo interpretativo. Sabemos, ainda, que o externo (...) importa não como causa, nem como significado, mas como elemento que desempenha um certo papel na constituição da estrutura, tornando-se, portanto, interno. (CANDIDO, 2000, p. 5-6)

Trata-se, portanto, no caso do poema "Inocentes do Leblon", de compreender que elementos, aparentemente exteriores ao texto, não são apenas referências temporais, espaciais ou históricas, são fatores indissociáveis à compreensão do poema como um todo, como linguagem e como arte.

Alfredo Bosi, em O ser e o tempo da poesia, formaliza a combinação que há entre a organização da linguagem poética e contextualização de um poema a ser estudado.

Contextualizar o poema não é simplesmente datá-lo: é inserir as suas imagens e pensamentos em uma trama já em si mesma multidimensional; uma trama em que o eu lírico vive ora experiências novas, ora anseios de mudança, ora suspensão desoladora de crenças e esperanças. A poesia pertence à Historia Geral, mas é preciso conhecer a história peculiar imanente e operante em cada poema. (BOSI, 2000, p. 13) 
Levando-se em conta a afirmação de Jauss de que a recepção das obras se dá de diferentes formas e em diferentes contextos, no curso do tempo, é possível observar que leitura contemporânea do poema "Inocentes do Leblon" pode propiciar significados diferentes daqueles provocados precisamente na época de sua produção.

A maneira pela qual uma obra literária, no momento histórico de sua aparição, atende, supera, decepciona ou contraria as expectativas de seu público inicial oferece-nos claramente um critério para a determinação de seu valor estético. (JAUSS, 1994, p. 31)

Mas há, de fato, um diálogo entre o texto e o leitor para o qual o texto foi escrito. Esse diálogo é estabelecido quando se procura recuperar a história de recepção de um texto como o que se fez acima como o poema "Inocentes do Leblon". Na estética da recepção é o que se chama de "reconstituição do horizonte" de uma obra.

Reconstituir o horizonte de um texto, portanto, é permitir perceber o seu valor estético e de fazer com que os alunos também possam percebê-lo. Ao ler, é possível observar o que o texto questionou no contexto em que foi escrito e ao que ele se contrapunha, é possível aprofundar ainda mais a leitura, ao estabelecer um diálogo com outros textos contemporâneos ou que, de alguma forma, se relacionam com ele.

Ao mostrar que leitura e texto podem ser vistos como pergunta e resposta, Regina Zilberman (1989) deixa claras as teorias da estética da recepção, na medida em que, ao ler, o leitor questiona, desvenda, quer saber mais sobre o texto. E, ao tentar chegar à pergunta original do texto, pode observar as sucessivas recepções que se pode buscar ao longo do tempo naquela obra, incluindo a comparação que se pode fazer entre o contexto no qual a obra foi escrita e o contexto no qual está sendo lida.

\section{Considerações finais}

Em sala de aula, torna-se fundamental chegar às particularidades da linguagem, aos sentidos do poema. Perceber esses valores em um texto literário, em particular, pode ser o motivo para percebê-los em tantos outros. Ao se estudar a literatura e suas especificidades, talvez seja possível se fazer um verdadeiro 
inventário, no sentido lato, de elementos fundamentais para a contextualização da obra e para tornar a aula de literatura ainda mais atraente. Isso porque a leitura do texto não será encarada como mera decodificação, mas como análise, compreensão e interpretação. Criando a possibilidade professor e alunos contemplarem a linguagem literária em seus múltiplos efeitos e tornarem as práticas de leitura mais significativas.

Ezequiel Teodoro da Silva lembra o papel do leitor crítico quando diz que:

(...) esse leitor aprendeu e sabe que determinadas leituras vão colocar a necessidade de escolha entre alternativas; outras, a contestação; outras, a aceitação; outras, ainda, a reflexão mais demorada e profunda para orientar a construção de um posicionamento futuro. (SILVA, 1989, p. 36)

Para tanto, o papel do professor pode ser o de garantir em sua aulas espaço para a análise e a interpretação, como elementos fundamentais para o enriquecimento da leitura e para o conhecimento e reconhecimento das obras literárias inseridas em um determinado contexto social, histórico, religioso, político, filosófico..., integrando teoria e prática.

\section{Referências bibliográficas}

AMADO, Genolino. "Os inocentes do Leblon". In AMADO, Genolino. Crônicas do Rio. Rio de Janeiro; Porto Alegre; São Paulo: Globo, 1946, p. 15-17.

ANDRADE, Carlos Drummond de. "Inocentes do Leblon". In Poesia Completa. Rio de Janeiro: Nova Aguilar, 2003, p.75.

BARTHES, Roland. Crítica e verdade. $3^{\underline{a}}$ ed. Tradução de Leyla Perrone-Moisés. São Paulo: Perspectiva, 2011.

CANDIDO, Antonio. Literatura e sociedade. São Paulo: Publifolha, 2000.

CICERO, Antonio. "Virgem”. In CICERO, Antonio. Guardar: poemas escolhidos. $4^{\mathrm{a}}$ ed. Rio de Janeiro: Record, 2008.

FREIRE, Paulo. A importância do ato de ler em três artigos que se completam. São Paulo: Cortez, 1992.

JAUSS, Hans Robert. A história da literatura como provocação à teoria literária. Tradução de Sérgio Tellaroli. São Paulo: Ática, 1994. 
LADEIRA, José Luís et al. (Orgs.). 0 tempo em gêneros. São Paulo: Salesiana, 2008.

MORICONI, Ítalo. Como e por que ler a poesia brasileira do século XX. Rio de Janeiro: Objetiva: 2002.

NITRINI, Sandra. "Teoria literária e literatura comparada". In Revista de Estudos Avançados. São Paulo: Instituto de Estudos Avançados da USP, vol.8, ํㅡ 22, 1994, p. 473-480.

PINTO, Manuel da Costa. "As paisagens interiores da literatura" Entrevista concedida a Luiz Costa Pereira Junior. In: Revista Língua Portuguesa. São Paulo: Segmento, ano 8, no 85, 2012, p. 10-13.

POUND, Ezra. "O que é literatura". In: ABC da literatura. São Paulo: Cultrix, 1994.

SILVA, Ezequiel Teodoro da. "Criticidade como elemento básico da qualidade da leitura”. In: Criticidade e Leitura: ensaios. Campinas: Mercado das Letras, 1998.

ZILBERMAN, Regina. Estética da recepção e história da literatura. São Paulo: Ática, 1989. 
Artigo recebido em: 14 de dezembro de 2014

Artigo aprovado em: 20 de abril de 2015

\section{Sobre o autor:}

Alberto Roiphe é vice-coordenador do Grupo Multidisciplinar de Estudo e Pesquisa em Arte e Educação do Departamento de Artes Plásticas da Escola de Comunicações e Artes da Universidade de São Paulo - ECA-USP; Membro do Grupo de Estudos em Leitura Literária da Universidade Federal de Sergipe - UFS; Membro do Grupo de Estudos Educação, Discurso e Mídia, da Universidade Federal do Estado do Rio de Janeiro - UNIRIO; Investigador/Colaborador do Centro de Estudos Interdisciplinares do Século XX da Universidade de Coimbra CEIS20. 